\title{
Effects of intensified training and taper on immune function
}

CDD. 20.ed. 616.079

796.073

Elena PAPACOSTA*

Michael GLEESON*
*School of Sport, Exercise and Health Sciences, Loughborouh University - United Kingdom.

\begin{abstract}
Although resting immune function is not very different in athletes compared with non-athletes periods of intensified training (overreaching) in already well trained athletes can result in a depression of immunity in the resting state. IIIness-prone athletes appear to have an altered cytokine response to antigen stimulation and exercise. Having low levels of salivary IgA secretion also makes athletes more susceptible to upper respiratory tract infections. Overtraining is associated with recurrent infections and immunodepression is common, but immune functions do not seem to be reliable markers of impending overtraining. There are several possible causes of the diminution of immune function associated with periods of heavy training. One mechanism may simply be the cumulative effects of repeated bouts of intense exercise (with or without tissue damage) with the consequent elevation of stress hormones, particularly glucocorticoids such as cortisol, causing temporary inhibition of $\mathrm{TH}-1$ cytokines with a relative dampening of the cell-mediated response. When exercise is repeated frequently there may not be sufficient time for the immune system to recover fully. Tapering has been described as a gradual reduction in the training load which allows the recovery of physiological capacities that were impaired by previous intensive training and permits further training-induced adaptations to occur accompanied by competition performance enhancements. The majority of the studies that have examined the recovery of immunoendocrine responses during 1-3 week tapers in trained athletes have mainly reported enhanced performance, often accompanied by increased anabolic activity, reduced physiological stress and restoration of mucosal immunity and immune function.
\end{abstract}

KEY WoRDs: Exercise training; Tapering; Immunity; Leukocytes; Immunoglobulins; Athletes.

\section{Introduction}

The relationship between exercise and susceptibility to upper respiratory tract infection (URTI) has been modelled in the form of a 'J'shaped curve as illustrated in FIGURE $1^{1}$ and the relationship between exercise load and immune function is modelled as the inverse (mirror image of this curve). This model suggests that while engaging in moderate activity may enhance immune function above sedentary levels, excessive amounts of prolonged high-intensity exercise induce detrimental effects on immune function. The literature provides strong evidence in support of the latter point ${ }^{1-7}$, though relatively little evidence is available to suggest that there is any clinically significant difference in immune function between sedentary and moderately active persons.

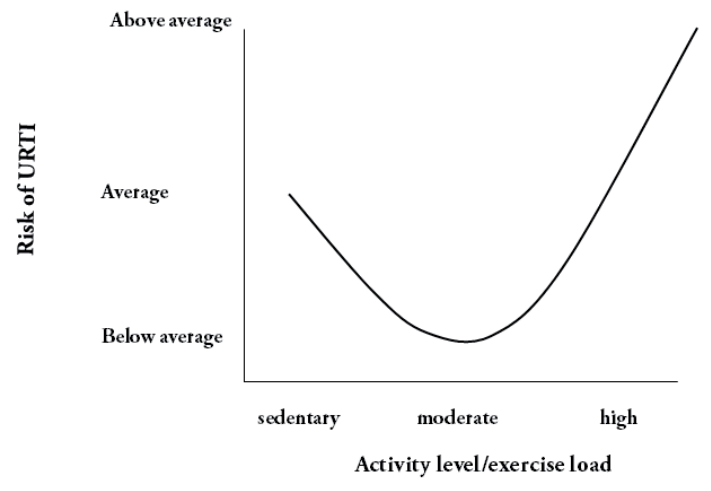

FIGURE 1 - The J-shaped model of the relationship between risk of upper respiratory tract infection (URTI) and exercise volume. (Adapted from NiEMAN ${ }^{1}$ ). 
Retrospective and prospective longitudinal studies have identified that the majority of elite athletes experience symptoms of URTI at a rate similar to the general population ${ }^{8-10}$, however, the episodes of URTI in elite athletes do not follow the usual seasonal patterns of URTI observed in the general population ${ }^{11}$ but rather occur during or around competitions ${ }^{12-16}$. Symptoms occur more frequently during the high intensity training and taper period prior to competitions in some sports, such as swimming and kayaking ${ }^{17-19}$, while in other endurance sports, such as long distance running, URTI symptoms appear more frequently in the athletes after a competition ${ }^{12-14}$. Illness-prone athletes may also be susceptible to URTI symptoms during regular training periods or following increases in the training load ${ }^{20}$. The short-term duration of URTI symptoms (1-3 days) reported in most studies suggests that in most instances a primary infection is unlikely and the symptoms may be due to viral reactivation ${ }^{13,21}$ or other causes of exercise-induced inflammation. For longer lasting episodes, typically of 4-10 days, a new infection, usually viral, is likely.

\section{Exercise training effects on innate immune function}

Regular exercise training does not appear to appreciably alter blood leukocyte counts ${ }^{22}$ however, there are a few reports that exercise training reduces blood neutrophil counts in those with chronic inflammatory conditions or neutrophils in sites of chronic inflammation ${ }^{23}$ raising the possibility that such exercise acts in an anti-inflammatory fashion in those with elevated inflammation. This effect could be beneficial or deleterious dependent upon the context. While there is little known about the influence of exercise training on neutrophil function, regular exercise, especially heavy, intense training, may attenuate neutrophil respiratory burst ${ }^{24-25}$. This could reflect a sustained effect of previous acute exercise as attenuation of respiratory burst has been documented to last several days post-exercise ${ }^{26}$. Both longitudinal exercise training and cross-sectional studies have shown that physically active persons exhibit reduced blood monocyte inflammatory responses to lipopolysaccharide, lower toll like receptor (TLR) expression, and a lower percentage of CD14+/CD16+ 'inflammatory' monocytes ${ }^{27}$. There are two reports from the same group demonstrating an effect of exercise training on rat dendritic cells.
LiAO et al. ${ }^{28}$ reported that dendritic cell number increased after training with no difference in costimulatory molecule (CD80 or CD86) expression while CHIANG et al. ${ }^{29}$ found that MHC II expression, mixed leukocyte reaction and interleukin (IL)-12 production were increased in dendritic cells from exercise trained rats. Clearly, given the importance of dendritic cells in early immune regulation, this is an area ripe for further investigation.

Despite much research regarding the effects of exercise training on natural killer (NK) cell number and function, there appears to be much controversy regarding its effect. Early cross-sectional studies or interventions with limited subject numbers reported modest increases in NK cell cytolytic activity (NKCA) after moderate exercise training in previously sedentary subjects ${ }^{7,30-34}$. In two of the larger trials, one study FAIREY et al. ${ }^{35}$ found that 15 weeks of moderate exercise training increased NKCA compared with sedentary controls, while another 12-month trial found no change in NKCA in 115 post-menopausal women ${ }^{36}$. However, periods of very intensive training have been shown to alter NK cell subsets and reduce NKCA ${ }^{5,37-38}$.

\section{Exercise training effects on mucosal immune function}

The production of secretory immunoglobulin A $(\operatorname{SIgA})$ is the major effector function of the mucosal immune system providing the 'first line of defence' against pathogens. To date, the majority of exercise studies have assessed saliva SIgA as a marker of mucosal immunity but more recently the importance of other antimicrobial proteins in saliva (e.g. $\alpha$-amylase, lactoferrin and lysozyme) has gained greater recognition. Acute bouts of moderate exercise have little impact on mucosal immunity but prolonged exercise and intensified training can evoke decreases in saliva secretion of SIgA. 
Mechanisms underlying the alterations in mucosal immunity with acute exercise are probably largely related to the activation of the sympathetic nervous system and its associated effects on salivary protein exocytosis and IgA transcytosis. Depressed secretion of SIgA into saliva during periods of intensified training and chronic stress are likely linked to altered activity of the hypothalamic-pituitary-adrenal axis with inhibitory effects on IgA synthesis and/or transcytosis. Several studies support the hypothesis that reduced levels of saliva SIgA are associated with increased risk of URTI during heavy training: While study populations vary, the association of an increased risk of URTI with lower concentrations of salivary $\operatorname{IgA}$ and/or secretion rates has been consistent for high-performance endurance athletes and games players undertaking intensive training regimens $s^{5,13-14,39-48}$ or participating in repeated competitions over several weeks ${ }^{49}$. Similarly, the increases in salivary SIgA observed after moderate exercise training may contribute to the reduced susceptibility to URTI associated with regular moderate exercise $\mathrm{e}^{50-51}$.

A high incidence of infections is reported in individuals with selective deficiency of SIgA ${ }^{52}$ or very low saliva flow rates ${ }^{53}$. Moreover, high levels of saliva SIgA are associated with low incidence of URTI $^{54}$ and low levels of saliva SIgA in athletes ${ }^{40,43,55}$ or substantial transient falls in saliva $\operatorname{SIgA}^{47}$ are associated with increased risk of URTI.

Levels of saliva SIgA vary widely between individuals and although some early studies indicated that saliva SIgA concentrations are lower in endurance athletes compared with sedentary individuals ${ }^{56}$, the majority of studies indicate that they are generally not different in athletes compared with non-athletes except when athletes are engaged in heavy training ${ }^{57-59}$.

\section{Exercise training effects on acquired immune function}

In the true resting state (i.e. more than $24 \mathrm{~h}$ after their last training session) circulating lymphocyte numbers and functions appear to be broadly similar in athletes compared with non-athletes ${ }^{60}$. Longitudinal studies in which previously sedentary people undertake weeks or months of exercise training have failed to show any marked changes in $\mathrm{T}$ and $\mathrm{B}$ cell functions provided that blood samples are taken at least 24 hours after their last exercise bout. In contrast, $\mathrm{T}$ and $\mathrm{B}$ cell functions appear to be sensitive to increases in training load in welltrained athletes undertaking a period of intensified training, with decreases in circulating numbers of Type $1 \mathrm{~T}$ cells, reduced $\mathrm{T}$ cell proliferative responses and falls in stimulated B cell Ig synthesis reported $^{61-63}$. This suggests that athletes engaging in longer periods of intensified training can exhibit decreases in $\mathrm{T}$ cell functionality. The cause of this depression in acquired immunity appears to be related to elevated circulating stress hormones, particularly cortisol, and alterations in the pro/ anti-inflammatory cytokine balance in response to exercise. This appears to result in a temporary inhibition of Type $1 \mathrm{~T}$ cell cytokine production with a relative dampening of the Type 1 (cell-mediated) response.

\section{Effects of intensified periods of exercise training on immune function}

The effects of relatively short-term (typically $1-3$ weeks) intensified exercise training periods on immune function have been investigated in several athlete groups. There also a few longitudinal studies that have monitored immune function in athletes over the course of a competitive season lasting typically 4-10 months. There are also a handful of small cross-sectional studies that have compared immune function in athletes diagnosed as "overtrained" with healthy athletes.
Athletes commonly intensify their training for a few days or weeks at certain stages of the season. This may induce a state of overreaching in which performance is temporarily reduced, but following a period of taper with only light training, results in supercompensation and an increase in performance. Several studies in recent years have investigated the effects of short periods of intensified training on resting immune function and on immunoendocrine responses to endurance 
exercise. These studies indicate that several indices of leukocyte function including neutrophil and monocyte oxidative burst, the T-lymphocyte CD4+/CD8+ ratio, mitogen-stimulated lymphocyte proliferation and antibody synthesis and NKCA are sensitive to increases in the training load in already well-trained athletes ${ }^{5,61,63-65}$. Even following relatively short periods (1-2 weeks) of intensified training marked reductions in neutrophil function, lymphocyte proliferation, SIgA and the circulating number of T-cells producing interferon-gamma (IFN- $\gamma$ ) have been observed ${ }^{18,63,65}$. For example, a 2 -week period of intensified training in already well-trained triathletes was associated with a 20\% fall in the lipopolysaccharide (LPS)-stimulated neutrophil degranulation response ${ }^{64}$ (TABLE 1) and after only 1 week of intensified training in well-trained cyclists substantial falls in both neutrophil oxidative burst activity and lymphocyte proliferation responses were observed ${ }^{65}$. Thus, with sustained periods of heavy training, several aspects of both innate and adaptive immunity are depressed, but athletes are not clinically immune deficient. In other words, exercise-induced immune dysfunction does not put athletes in danger of serious illness, but it could be sufficient to increase the risk of picking up common infections such as URTI, or influenza should the dreaded outbreak occur.

TABLE 1 - Effects of an acute increase in the training load on some immune variables in elite athletes. Data from (A) Robson et al. ${ }^{66}$ and (B) VERDE et al. ${ }^{61}$.

LPS = lipopolysaccharide; $\mathrm{CK}=$ creatine kinase; $C D=$ clusters of differentiation; $\mathrm{Ig}=$ immunoglobulin. a elastase release in response to stimulation with bacterial LPS.

(A) Training was intensified over a 2-week period by the imposition of additional interval training sessions on top of the normal endurance training of eight male triathletes. Data are means \pm SEM. ${ }^{*} \mathrm{P}<0.05$ : significant effect of additional training.

\begin{tabular}{lcc}
\hline & Normal training & Intensified training \\
Saliva IgA (mg/L) & $115 \pm 21$ & $104 \pm 25$ \\
Total leukocyte count $\left(\mathrm{x} 10^{9} / \mathrm{L}\right)$ & $4.6 \pm 0.2$ & $5.1 \pm 0.2$ \\
Neutrophil count $\left(\mathrm{x} 10^{9} / \mathrm{L}\right)$ & $2.3 \pm 0.2$ & $2.7 \pm 0.2$ \\
Neutrophil degranulation $(\mathrm{fg} / \mathrm{cell})^{\mathrm{a}}$ & $166 \pm 13$ & $111 \pm 7^{*}$
\end{tabular}

(B) Weekly training distance was increased by $35 \%$ above the normal training for 3 weeks in ten male distance runners. Data are means (SEM). ${ }^{*} \mathrm{P}<0.05$ : significant effect of additional training.

\begin{tabular}{lcc} 
& Normal training & Intensified training \\
T-cell CD4+/CD8+ ratio & $2.91 \pm 0.71$ & $2.05 \pm 0.32^{*}$ \\
Mitogen-induced IgG synthesis $(\mu \mathrm{g} / \mathrm{L})$ & $644 \pm 207$ & $537 \pm 130^{*}$ \\
Mitogen-induced IgM synthesis $(\mu \mathrm{g} / \mathrm{L})$ & $730 \pm 190$ & $585 \pm 445^{*}$ \\
\hline
\end{tabular}

Several longitudinal studies have monitored mucosal immune function in high-level athletes such as cyclists ${ }^{62}$, swimmers ${ }^{5,18}$ and footballers ${ }^{43,67-68}$ over the course of a competitive season. In a study of American football players, the incidence of URTI was increased during intense training (FIGURE 2) and this was associated with falls in SIgA concentration and secretion rate. In that study it was reported that the secretion rate of SIgA (which represents the amount of SIgA available on the mucosal surfaces for protection against pathogens) was significantly and inversely related to URTI incidence ${ }^{43}$. In an earlier and much cited study, the impact of longterm training on systemic and mucosal immunity was assessed prospectively in a cohort of elite Australian swimmers over a 7-month training season in preparation for the national championships ${ }^{5,40}$. The results indicated significant depression of resting serum and salivary immunoglobulin concentrations in athletes, associated with long-term training at an intensive level. Furthermore, resting SIgA concentrations at the start of the training period showed significant correlations with infection rates (FIGURE 3) and the number of infections observed in the swimmers was predicted by the pre-season and mean pre-training SIgA levels (FIGURE 4). Among the markers of systemic immunity that were also measured there were no significant changes in numbers or percentages of $\mathrm{B}$ or $\mathrm{T}$ cell subsets, but there was a significant fall in natural killer (NK) cell numbers and percentages in the swimmers over the training season. 
(A)

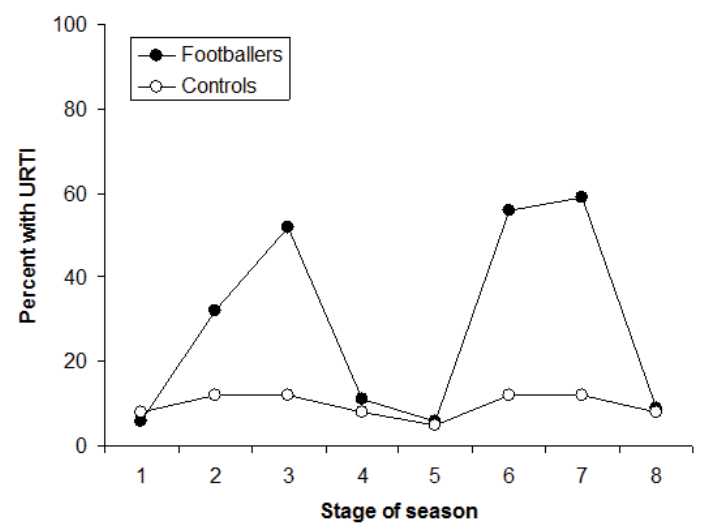

(B)

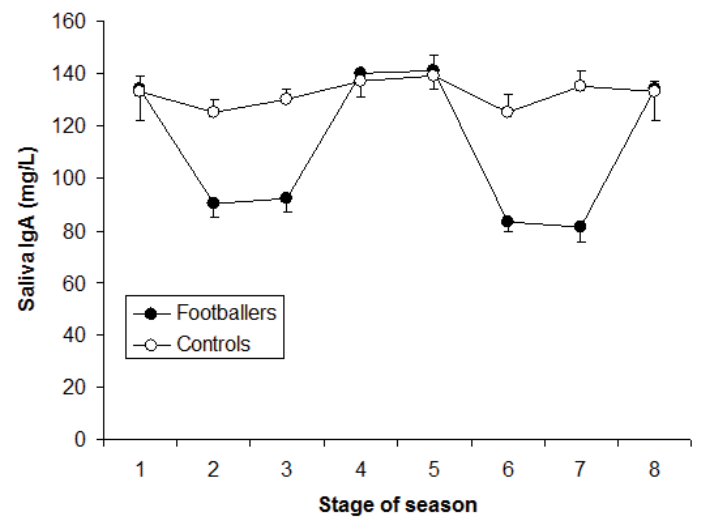

FIGURE 2 - URTI incidence (A) and SIgA concentrations (B) among male college American Footballers (N = 75) and recreationally active male controls $(\mathrm{N}=25)$ over a season of training and competition. The most intensive training and competition periods were in autumn (periods 2 and 3) and spring (periods 6 and 7). Adapted from FAHLMAN and ENGELS ${ }^{43}$.

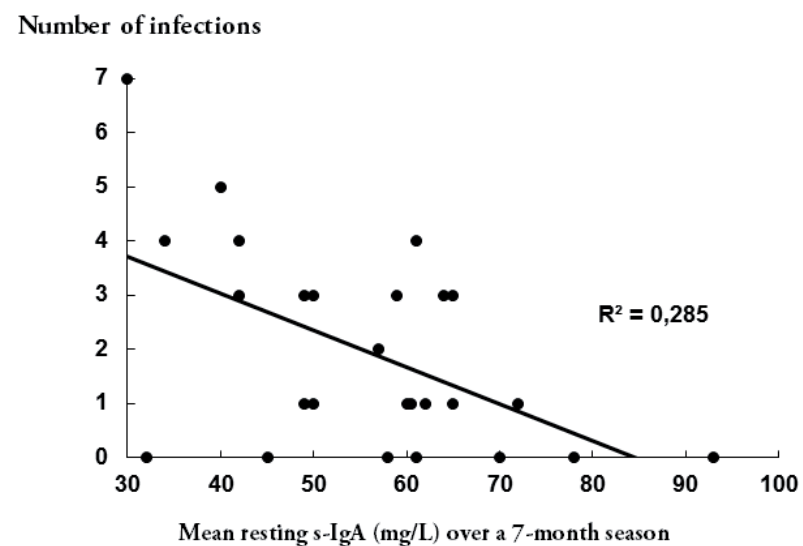

FIGURE 3 - The relationship between resting saliva IgA concentration and incidence of infection among 26 elite swimmers during a 7-month training season. Resting IgA fell during the 7-month training period on average by $4.1 \%$ per month of training and infection incidence was more frequent towards the end of the training period. Data from GLEESON et al.5. 


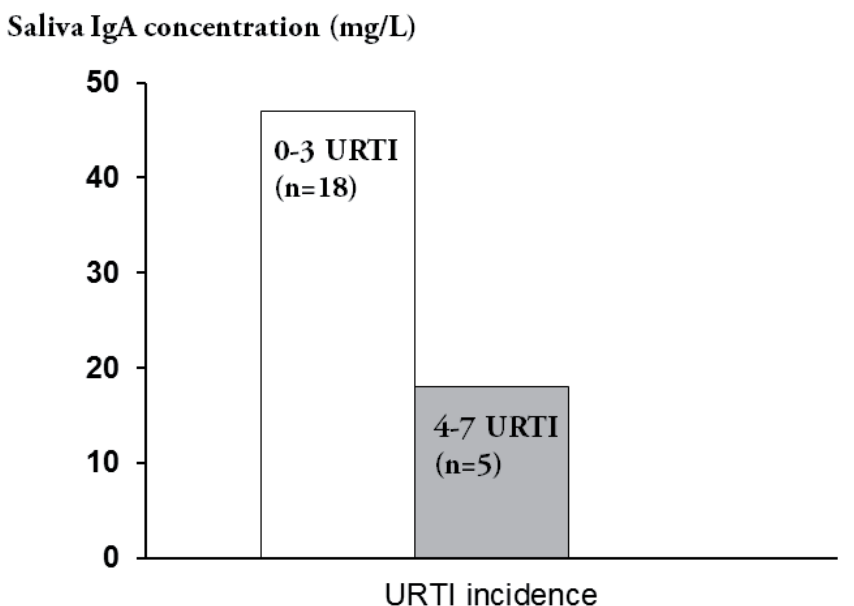

FIGURE 4 - Swimmers with resting saliva IgA concentrations below $30 \mathrm{mg} / \mathrm{L}$ had a higher incidence of infections (4-7 episodes) than swimmers with higher IgA levels (0-3 episodes) duringa 7-month training season. From GLEESON ${ }^{18}$.

Another study monitored elite yachtsmen over 50 weeks of training and competition and reported an inverse (i.e., negative) association between SIgA levels and training load as well as a significant inverse association between SIgA levels and URTI incidence ${ }^{47}$. Furthermore, retrospective analysis of infection episodes and SIgA levels indicated that prior to URTI episodes occurring SIgA levels fell in the preceding 2-3 weeks (FIGURE 5).

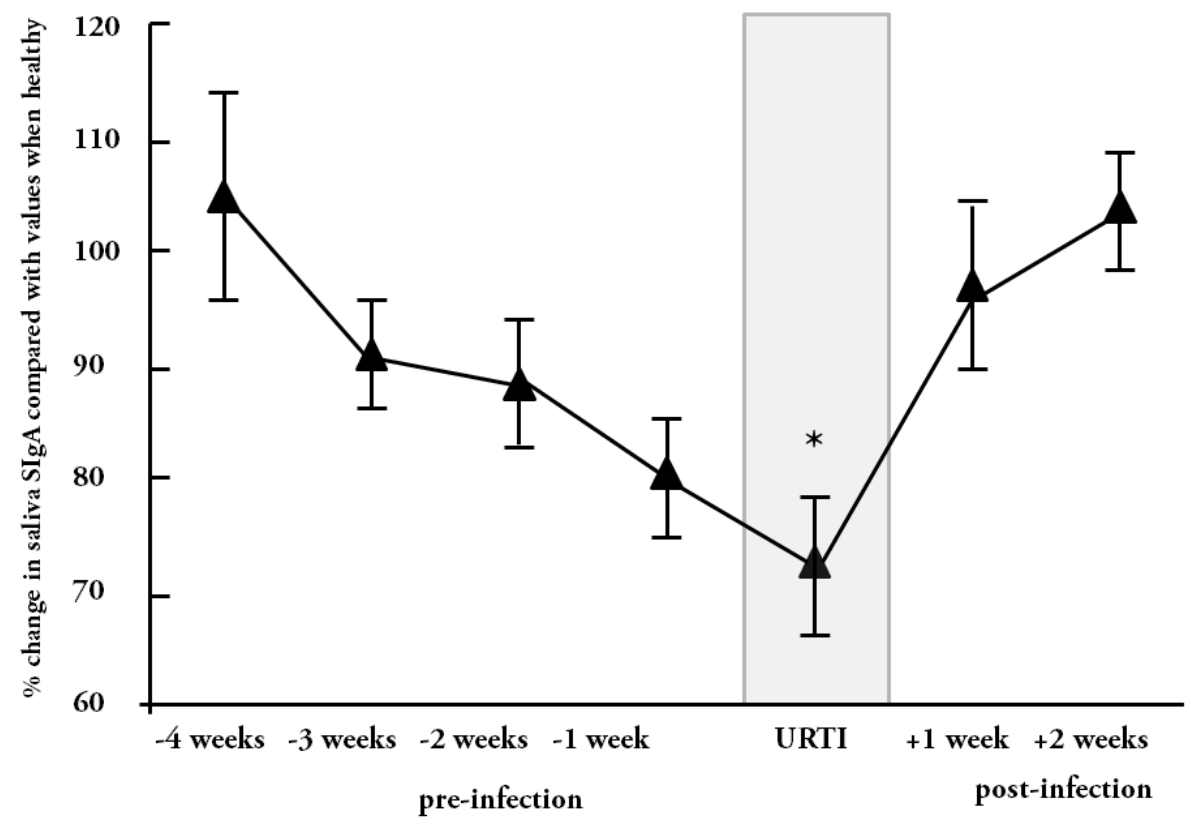

FIGURE 5 - SIgA concentration for each week before (Pre) during, and after (Post) all URTI episodes $(\mathrm{N}=102)$ in a cohort of elite yachtsmen $(\mathrm{N}=38)$ monitored over a 50 -week period of training and competition. Data are mean \pm SEM of individual relative SIgA (\% of healthy values). *URTI significantly different from $-4 \mathrm{wk},+1 \mathrm{wk}$, and $+2 \mathrm{wk}, \mathrm{P}<0.005 ;{ }^{*}-1 \mathrm{wk}$ significantly different from $+2 \mathrm{wk}, \mathrm{P}<0.005$. Note that falls in SIgA below healthy baseline values for 2-3 weeks preceded URTI episodes. Data from Neville et al. ${ }^{47}$.

These studies on mucosal immunity in athletes are representative of a very small number of studies that have established a relationship between some surrogate measure of immune function and infection incidence in athletes. A few studies on soldiers during intensive periods of military training have also reported a negative relationship between SIgA concentration and occurrence of URTI ${ }^{69}$, though others have not ${ }^{70-71}$. SIgA was evaluated as a marker of the severity of stress during a 19-day Royal Australian 
Air Force (RAAF) survival course, during which the 29 participants experienced hunger, thirst, boredom, loneliness, and extreme heat and cold combined with demanding physical effort ${ }^{69}$. Dietary restriction, consumption of alcohol, body mass loss, occurrence of URTI, and negative emotions were negatively associated with SIgA or the ratio of SIgA to Albumin and the authors concluded that this ratio is a useful marker of the severity of stresses encountered during stressful training. Another study examined the impact of a 3-week period of military training followed by an intensive 5-day combat course in 21 French Commandos on SIgA levels and incidence of URTI ${ }^{71}$. Resting saliva samples were collected in the morning just before entry into the Commando training, and the mornings following the 3 -week training period, after the 5-day combat course and after one week of recovery. After the 3-week training period, the SIgA concentration was not changed, although it was reduced by $-40 \%$ after the 5 -day course and returned to pre-training levels within a week of recovery. The incidence of URTI increased during the trial but was not related to SIgA. Among the thirty episodes of URTI reported, there were 12 rhino-pharyngitis, 6 bronchitis, 5 tonsillitis, 4 sinusitis and 3 otitis. This study indicates that sustained stressful situations have an adverse effect on mucosal immunity and incidence of URTI, though a causal relationship between the two could not be established. However, in these military personnel studies the training often involves not only strenuous physical activity, but also dietary energy deficiency, sleep deprivation and psychological challenges. These multiple stressors are likely to induce a pattern of immunoendocrine responses that amplify the exercise-induced alterations.

In a study on competitive cyclists, the total number of leukocytes, $T$ lymphocyte subsets, mitogen-induced lymphocyte proliferation and IL-2 production, adherence capacity and oxidative burst activity of neutrophils were measured at rest at the beginning of a training season and after six months of intensive training and a racing season, cycling approximately $500 \mathrm{~km}$ a week ${ }^{62}$. Baseline values of the tested immune parameters were within the range observed in non-trained healthy controls. At the end of the season significant decreases in absolute numbers of CD3 + and CD4+ cells, diminished IL-2 production and reduced fMLP and PMA stimulated oxidative burst activity of neutrophils were noted. Surprisingly, a marked increase in lymphocyte proliferation induced by PHA and anti-CD3 were also observed at rest after the training season.
In a study of 18 national level swimmers and 11 healthy nonathlete volunteers, blood samples were collected from athletes after 36 hours of resting recovery from exercise at four times during the training season and at similar times from the nonathlete controls ${ }^{37}$. The samples were incubated in the presence or the absence of LPS and IFN- $\gamma$ and the frequency of cytokine producing neutrophils, monocytes and dendritic cells and the amount of each cytokine produced per cell were evaluated by flow cytometry. In addition, plasma cortisol levels were measured and upper respiratory symptoms recorded through daily logs. In the athletes, but not in the controls, a decrease in the number of monocytes, neutrophils and dendritic cell subsets and in the amount of IL-1 $\beta$, IL- 6 , IL-12, tumour necrosis factor alpha (TNF- $\alpha$ ) and macrophage inflammatory protein 1-beta (MIP-1 $\beta$ ) produced by these cells in response to stimulation, was observed over the training season. The differences were most noticeable between the first (baseline values) and second blood collections, corresponding to the initial elevation of training volume. In the athletes the plasma levels of cortisol partially correlated with training intensity and could, at least in part, explain the reduced response of cells to stimulation in vitro. The results from this study support the idea that long term intensive training may affect the function of innate and antigen-presenting immune cells, reducing their capacity to respond to acute challenges, possibly contributing to an elevated risk of URTI.

There are only a few studies that have examined immunological changes in professional football players before, during and after a full season. BURY et al. ${ }^{67}$ reported that a competitive season in 15 Belgian professionals did not produce any change in the total number of leukocytes but increased neutrophil counts and decreased CD4+ T-lymphocyte counts. They also reported a slight decrease in $\mathrm{T}$ cell proliferation and a significant decrease in neutrophil function. On the other hand, training and competitions did not induce significant changes in the number of NK cells nor NK cytotoxic activity. ReBELO et al..$^{68}$ examined the effect of a soccer season on circulating leukocyte and lymphocyte subpopulations of 13 Portuguese players. At the end of the season total leukocyte and neutrophil numbers and CD8+ cells were increased compared to pre season values and the CD4/CD8 ratio was decreased.

Few studies have investigated the effects of intensified training on multiple markers of immune function. However, in one such study ${ }^{65}$, seven 
healthy endurance-trained men completed three trials consisting of cycling exercise at a work rate equivalent to $74 \% \mathrm{VO}_{2 \max }$ until volitional fatigue. The trials took place in the morning, before and after a 6-day period of intensified training (IT) and after 2 weeks of light recovery training (RT). Normal training (NT) consisted of -10 hours of cycling per week; during the ITP, training load was increased on average by $73 \%$. During RT, exercise was limited to no more than $4 \mathrm{~h}$ per week for 2 weeks. Training intensity and duration were confirmed by the use of heart rate monitors. The percentage and number of T-cells producing IFN $-\gamma^{+}$was lower at rest following the IT period compared with normal training (TABLE 2). Ex vivo stimulated neutrophil oxidative burst activity and lymphocyte proliferation fell after acute exercise and were markedly depressed at rest after the IT period (FIGURE 6) compared with normal training. Ex vivo stimulated monocyte oxidative burst activity

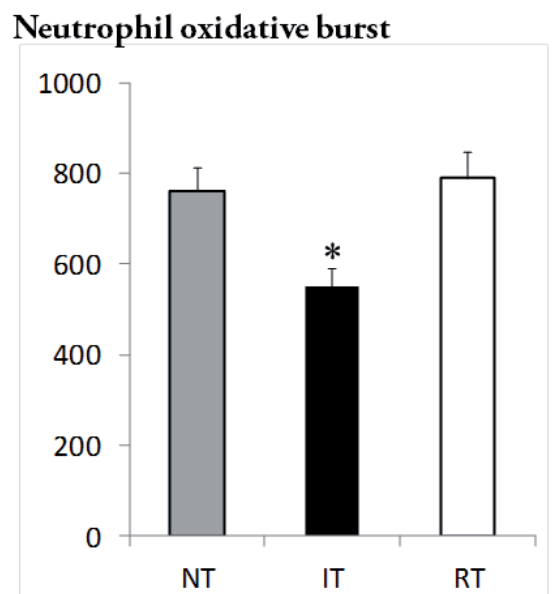

was unchanged after acute exercise, but was lower at rest following the IT period compared with normal training. Following all acute exercise trials the circulating number of IFN- $\gamma^{+}$T-cells and the amount of IFN $-\gamma$ produced per cell was decreased. The 6 days of intensified training did not affect resting SIgA concentration, but the latter was significantly lower at the end of RT (SIgA values were $74.2 \pm 13.1,64.6 \pm 12.5$ and $49.0 \pm 10.4 \mathrm{mg} / \mathrm{L}$ during NT, IT and RT, respectively). Except for SIgA, all measured immune parameters were back to normal after 2 weeks of RT. These results indicate that: 1) acute exhaustive exercise causes a temporary fall in several aspects of immune cell function and a decrease in IFN- $\gamma$ production by T cells; 2 ) resting immune function is decreased after only 6 days of intensified training and these effects are reversible with two weeks of relative rest; 3) in general the immune response to an acute bout of exhaustive exercise is not affected by the weekly training load.

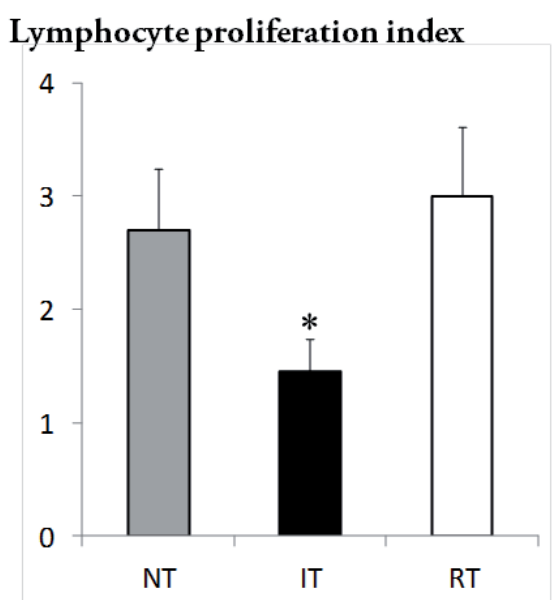

FIGURE 6 - Neutrophil oxidative burst activity (Mean Fluorescence Intensity, MFI) and mitogen-stimulated lymphocyte proliferation (Stimulation Index, SI) in blood taken at rest in the morning during normal training (NT), after 1 week of intensified training (IT) and after 2 weeks of light recovery training (RT). Data from LANCASTER et al. ${ }^{65}$. *Significantly different from NT.

Although elite athletes are not clinically immune deficient, it is possible that the combined effects of small changes in several immune parameters may compromise resistance to common minor illnesses such as URTI. Protracted immune depression linked with prolonged intensive training may determine susceptibility to infection, particularly at times of major competitions. 


\section{Tapering and the timecourse of immune system recovery after intensive training}

Tapering has been described as a gradual reduction in the training load which allows the recovery of physiological capacities that were impaired by previous intensive training and subsequently should restore the tolerance to training, resulting in further training-induced adaptations accompanied by competition performance enhancements ${ }^{72}$. The majority of the studies that have examined the recovery of immunoendocrine responses during 1-3 week tapers in trained athletes have mainly reported enhancements in performance, often accompanied by increased anabolic activity, reduction of exerciseinduced physiological stress and restoration of mucosal immunity and immune function ${ }^{73}$.

A tendency for increased lymphocyte and decreased neutrophil count was observed after a 4-week taper in elite level swimmers, despite no changes in circulating cortisol levels ${ }^{74}$. Interestingly, the increase in lymphocytes in this study was positively related with the reduction in training volume during the taper $(\mathrm{r}=0.86)$. Another, more recent study showed small but significant increases in neutrophil and granulocyte counts which were accompanied by improvements in $800-\mathrm{m}$ performance after a 6-day taper in middle-distance runners $^{75}$. In contrast, there are a number of studies reporting no changes in immune function, despite improvements in performance, increased anabolic activity and decreased catabolism during periods of tapering. Tapering for 2 weeks in triathletes ${ }^{76}$, for 1 week in rugby league players ${ }^{77-78}$ and for 2 weeks in judo athletes ${ }^{79}$ resulted in increased T/C ratio and improvements in performance. However, in two of these studies there were no changes in resting number of circulating leukocytes and subsets ${ }^{76,78}$. Similar results come from HALSON et al. ${ }^{80}$, demonstrating unchanged resting blood immune cell status and plasma levels of TNF- $\alpha$ and IL- 6 during 2 weeks of intensive training and tapering, despite improvements in performance, decreased plasma creatine kinase levels and a return of the plasma glutamine/glutamate ratio to baseline after the 2 -week tapering period. Another study investigated the responses of pro-inflammatory cytokines and endurance performance in elite male cyclists during 8 weeks of heavy endurance training and 3 weeks of tapering ${ }^{81}$. This study reported increases in plasma IL1 $\beta$, IL- 6 and TNF- $\alpha$ after the 3-week taper but not during the first week of the tapering period.
Interestingly, performance improved from the first week of tapering and was maintained until the third tapering week. The restoration or enhancement of immune function during tapering may be related to the severity of immune system suppression during the previous phase of intensive training. Consequently, there is no strong evidence to support the notion that changes in resting immune status or pro-inflammatory cytokines during tapering have any clinical significance for the athletes' competition performance.

Engaging in heavy training involving bouts of high intensity or high volume for prolonged periods of time has been reported to decrease salivary SIgA concentrations ${ }^{59}$. SIgA levels are negatively related to the incidence of URTI ${ }^{43}$, so traininginduced falls in SIgA could make athletes more susceptible to picking up common infections which could be detrimental during competition periods. Limited evidence exists regarding the restoration of mucosal immunity during tapering periods. One study reported non-significant decreases in resting SIgA concentrations during 2 weeks of intensified training which displayed some rise to baseline by the end of the 2-week recovery training period $^{80}$. However, no strict control of tapering was evident in this study. A recent study from our laboratory confirmed these findings, showing that SIgA concentrations and secretion rate significantly increased from baseline during a 2-week taper in judo athletes ${ }^{79}$. Even though no significant decreases were observed during the 2 -week intensive training period, SIgA levels and secretion rate doubled by the late stages of taper. During this study we also observed decreased salivary cortisol, increased salivary testosterone concentrations, which were accompanied by improvements in anaerobic and power-related performance during the early stages of tapering. Thus, it appears from this study that endocrine and performance changes precede the changes in mucosal immunity during a 2 -week taper. Although there is no compelling evidence that athletes are clinically immune-deficient during periods of intensive training, mucosal immunity seems to be more sensitive to changes in the training load. Tapering before competitions can restore athletes' immune function, presumably reducing the risk of picking up common URTI infections which may indirectly impair competition performance. 


\section{Comparisons of illness-prone athletes with healthy athletes}

Within the general healthy human population there is a range of immuno-competency due to genetic differences, sex differences, age, and lifestyle habits. Clearly, some individuals are more prone to illness than others (this is true for both the sedentary population and the athletic population) but it is not known which particular aspects of immune function (or dysfunction) are responsible for these differences in illness susceptibility. Biomarkers to predict infections could be of significant value among athletes and military personnel. As mentioned previously several studies have reported associations between decreased SIgA concentration or secretion rate and URTI incidence in athletes ${ }^{40,43,47}$ but these have been based on a relatively small number of subjects. Associations between URTI risk and blood immune parameters have not been extensively examined, though an impaired IFN- $\gamma$ production in unstimulated whole blood culture has been reported in fatigued and illness-prone endurance athletes ${ }^{82}$. However, the relevance of this measure of immune function to infection risk is unclear as cytokine production in the unstimulated state is very low compared with the response to an infectious agent or antigen challenge.

One recent study attempted to examine immune factors (including the cytokine response to antigen challenge) influencing susceptibility to upper respiratory tract infections (URTI) in men and women engaged in endurance-based physical activity during the winter months ${ }^{55}$. Eighty individuals provided resting blood and saliva samples for determination of markers of systemic immunity and each individual kept weekly training and illness logs for the following 4 months. Thirty of the subjects did not experience an URTI episode and 24 subjects experienced 3 or more weeks of URTI symptoms. Retrospective analysis revealed that these illness-prone subjects had higher training loads and had -2.5 -fold higher IL- 4 and IL-10 production by multiantigen-stimulated whole blood culture than the illness-free subjects (TABLE 2). Illness-prone subjects also had significantly lower saliva SIgA secretion and saliva flow rate than the illness-free subjects. There were no differences in circulating numbers of leukocyte subtypes, lymphocyte subsets or plasma levels of IgA and IgG between the illness-prone and illness-free subjects. The production of IL-10 was positively correlated and the SIgA secretion rate was negatively correlated with the number of weeks with URTI symptoms. The authors concluded that high IL-10 production in response to antigen challenge and low SIgA secretion are risk factors for development of URTI in physically active individuals. The significance of IL-10 may be its anti-inflammatory and immunosuppressive effects. Individuals that produce relatively large amounts of IL-10 during the early stages of an infection may not mount a sufficiently robust immune response to counter the pathogen and consequently may be more prone to developing the symptoms of infection. The results of this study also indicated that saliva flow rate is also an important factor in URTI risk. This might reflect the importance of other antimicrobial proteins (AMPs) in saliva such as amylase, defensins, lysozyme and lactoferrin ${ }^{83}$ in addition to SIgA. The multiple of the saliva flow rate and the saliva concentration of these AMPs determines their secretion rates into the oral cavity.

TABLE 2 - Differences between illness-prone subjects $(n=24)$ and illness-free subjects $(n=30)$. Data from GLEESON et al. ${ }^{55}$.

Values are expressed as mean $( \pm S D)$. Cytokine levels are those observed after $24 \mathrm{~h}$ in vitro incubation of whole blood with a multiantigen vaccine.

\begin{tabular}{lccc}
\hline & Illness-prone & Illness-free & P \\
\hline URTI (weeks) & $4.7 \pm 2.2$ & $0.0 \pm 0.0$ & 0.001 \\
Training load (h/week) & $10.7 \pm 4.6$ & $8.4 \pm 4.4$ & 0.046 \\
Saliva flow rate $(\mathrm{mL} / \mathrm{min})$ & $0.35 \pm 0.19$ & $0.53 \pm 0.24$ & 0.004 \\
SIgA concentration $(\mathrm{mg} / \mathrm{L})$ & $145 \pm 79$ & $155 \pm 95$ & 0.835 \\
SIgA secretion rate $(\mu \mathrm{g} / \mathrm{min})$ & $49 \pm 36$ & $80 \pm 53$ & 0.019 \\
& & & 0.183 \\
Plasma IgA $(\mathrm{g} / \mathrm{L})$ & $1.38 \pm 0.51$ & $1.64 \pm 0.80$ & 0.378 \\
Plasma IgG $(\mathrm{g} / \mathrm{L})$ & $10.75 \pm 1.83$ & $11.31 \pm 2.59$ & continues
\end{tabular}


TABLE 2 - Differences between illness-prone subjects $(n=24)$ and illness-free subjects $(n=30)$. Data from GLEESON et al. ${ }^{55}$ (continuation).

\begin{tabular}{lccc}
\hline & Illness-prone & Illness-free & P \\
\hline Leukocyte count $\left(x 10^{9} / \mathrm{L}\right)$ & $5.72 \pm 1.88$ & $5.78 \pm 1.19$ & 0.890 \\
Neutrophil count $\left(\mathrm{x} 10^{9} / \mathrm{L}\right)$ & $3.00 \pm 1.46$ & $2.94 \pm 0.98$ & 0.844 \\
Monocyte count $\left(\mathrm{x} 10^{9} / \mathrm{L}\right)$ & $0.48 \pm 0.21$ & $0.49 \pm 0.13$ & 0.831 \\
Lymphocyte count $\left(\mathrm{x} 10^{9} / \mathrm{L}\right)$ & $1.96 \pm 0.56$ & $2.13 \pm 0.59$ & 0.300 \\
T cell count $\left(\mathrm{x} 10^{9} / \mathrm{L}\right)$ & $1.21 \pm 0.45$ & $1.26 \pm 0.42$ & 0.688 \\
B cell count $\left(\mathrm{x} 10^{9} / \mathrm{L}\right)$ & $0.19 \pm 0.08$ & $0.23 \pm 0.14$ & 0.184 \\
NK cell count $\left(\mathrm{x} 10^{9} / \mathrm{L}\right)$ & $0.22 \pm 0.11$ & $0.25 \pm 0.15$ & 0.415 \\
& & & 0.683 \\
IL-1 $\beta$ production $(\mathrm{pg} / \mathrm{ml})$ & $8.2 \pm 7.1$ & $8.5 \pm 10.9$ & 0.064 \\
IL-2 production $(\mathrm{pg} / \mathrm{ml})$ & $189 \pm 258$ & $76 \pm 102$ & 0.018 \\
IL-4 production $(\mathrm{pg} / \mathrm{ml})$ & $6.2 \pm 9.6$ & $2.3 \pm 1.2$ & 0.094 \\
IL-6 production $(\mathrm{pg} / \mathrm{ml})$ & $188 \pm 137$ & $126 \pm 128$ & 0.264 \\
IL-8 production $(\mathrm{pg} / \mathrm{ml})$ & $1119 \pm 705$ & $927 \pm 717$ & 0.008 \\
IL-10 production $(\mathrm{pg} / \mathrm{ml})$ & $6.8 \pm 7.7$ & $2.4 \pm 2.5$ & 0.060 \\
IFN- $\gamma$ production $(\mathrm{pg} / \mathrm{ml})$ & $40 \pm 62$ & $26 \pm 71$ & 0.166 \\
TNF- $\alpha$ production $(\mathrm{pg} / \mathrm{ml})$ & $28 \pm 32$ & $26 \pm 55$ & \\
\hline
\end{tabular}

Values are expressed as mean $( \pm S D)$. Cytokine levels are those observed after $24 \mathrm{~h}$ in vitro incubation of whole blood with a multiantigen vaccine.
A few other small-scale studies have attempted to determine if cytokine responses to exercise differ between healthy and illness-prone distance runners. One such study by Cox et al. ${ }^{84}$ classified runners as healthy (no more than two episodes of upper-respiratory symptoms per year; $\mathrm{N}=10$ ) or illness-prone (four or more episodes per year; $\mathrm{N}=$ 8 ) and reported that the resting plasma IL-8, IL-10, and IL-1ra concentrations were $19-38 \%$ lower in illness-prone runners. After a standardised bout of treadmill running, post-exercise plasma IL-10 and IL-1 ra concentrations were $10-20 \%$ lower, whereas
IL-6 elevations were $84-185 \%$ higher in illnessprone subjects suggesting that cytokine responses to exercise differ between healthy and illness-prone athletes. This might reflect impaired inflammatory regulation in the hours after exercise that may account for the greater frequency of upper-respiratory symptoms experienced. Such differences in cytokine production in response to exercise or infection may be, at least in part, due to differences in cytokine gene polymorphisms ${ }^{85}$ but more work is needed to establish if this is an important factor influencing illness risk among athletes or other populations.

\section{Effects of overtraining on immunity}

As athletes strive to produce improved performances, they are under pressure to increase their training load; this is epitomised by the Olympic motto 'citius, altius, fortius' (faster, higher, stronger). Paradoxically, there is much anecdotal evidence cited in the literature that links excessive exercise with a chronic decrement in athletic performance. This is highlighted by elite athletes failing to improve last year's performances despite undergoing ever more intensive training programmes or athletes reporting an inability to regain previous form following a tough competition.
An athlete must undergo significant stress during training in order to provide sufficient stimulus for physiological adaptation and the subsequent improvement in performance. To ensure that the athlete adapts favourably to the training load, imposed adequate rest is a crucial part of any training programme. If rest is not sufficient and the exercise stress alone or combined with other stressors (physical, nutritional, environmental or psychological) is too great, the athlete may fail to adapt (maladapt) and become overreached. If insufficient rest continues 
when overreached and the athlete is exposed to further stressors, then a state of chronic fatigue, nonrecovery and, in some instances, immunodepression may occur; this is classified as overtraining syndrome (OTS) and is sometimes referred to as unexplained underperformance syndrome. For an up-to-date review on the diagnosis, treatment and prevention of OTS see MEEUSEN et al. ${ }^{86}$.

Anecodotal reports from athletes and coaches of an increased infection rate with OTS have also been supported by several empirical studies. In a cohort study of highly trained athletes prior to the Olympic Games, over $50 \%$ of the athletes who reported symptoms of OTS presented with infection compared with none of the athletes in the overreached group $^{87}$. It appears, therefore, that suppression of immune system function as a consequence of excessive physical and/or psychological stress can clinically manifest as an increased susceptibility to infectious illness, particularly URTI.

\section{Hypotheses to explain immunodepression in OTS}

There are several possible causes of the diminution of immune function associated with periods of heavy training. Although, at present, there is no encompassing theory to explain the altered immune competence experienced by athletes with OTS, several hypotheses have been proposed.

\section{Glutamine hypothesis}

The most frequently cited theory is the glutamine hypothesis of overtraining ${ }^{88}$. Glutamine is an amino acid essential for the optimal functioning of lymphocytes and, in vitro studies have demonstrated that in the absence of glutamine lymphocytes are unable to proliferate. Since, many athletes with OTS, and those undergoing intense exercising training, present with low plasma glutamine concentration ${ }^{87,89-90}$, it is hypothesised that the fall in plasma glutamine levels cause lymphocyte function to become depressed, thus rendering the athlete more susceptible to infections. However, a weakness in this theory concerns the in vitro studies. When lymphocytes are cultured with identical glutamine concentrations to the lowest plasma glutamine concentrations reported in athletes following intense exercise or with OTS (300-400 $\mu \mathrm{M})$, lymphocyte proliferation and lymphokineactivated killing cell activity are identical to when they are cultured in normal resting glutamine levels $(600 \mu \mathrm{M})$. Furthermore, KINGSBURY et al. ${ }^{87}$ found no differences in the plasma glutamine concentrations of athletes with OTS either with or without infections. Although plasma glutamine does not appear to be involved with exercise-induced immunodepression, it may still provide a useful marker of excessive exercise and impending OTS.

\section{Open Window theory}

An alternative theory is the 'open window' theory, as detailed previously. The period of postexercise suppression of some aspects of the immune system has been identified as a potential window of opportunity for infections. This window can remain open between 3-72 hours (though in most cases 3-24 $\mathrm{h}$ is probably the norm) following exercise during which an infectious agent may be able to gain a foothold on the host and increase the risk of an opportunistic infection ${ }^{91}$. It is feasible that the combination of stressors that lead to the onset of OTS in athletes may cause the post-exercise 'window of vulnerability to infection' to be open for a longer period, consequently, rendering the athlete with OTS more susceptible to infection.

\section{Tissue injury or cytokine theory}

The most recent theory, which holds much promise, is the 'tissue injury theory' of immunodepression in UPS proposed by SMITH ${ }^{92-93}$. Over the past decade, it has been established that $\mathrm{T}$ helper lymphocytes $(\mathrm{TH})$, an integral part of immune function comprise two functional subsets namely $\mathrm{TH}-1$ and $\mathrm{TH}-2$ which are associated with cell-mediated immunity and humoral immunity, respectively. When TH-precursor cells are activated, one subset is upregulated in favour of the other subset such that either the $\mathrm{TH}-1$ or the $\mathrm{TH}-2$ lymphocytes are activated depending on the nature of the stimulus. The upregulation of one subset over the other is determined by the predominant circulating cytokine pattern. The tissue injury theory proposes that the exercise-induced immunodepression in UPS is due to excessive tissue trauma (i.e. muscle fibre 
damage) induced by intense exercise with insufficient rest, which produces a pattern of cytokines that drive the TH-2 lymphocyte profile. The upregulation of the TH-2 lymphocytes is further augmented by the elevation of circulating glucocorticoids, catecholamines and prostaglandin E2 following prolonged exercise. The TH-2 proliferation results in a suppression of the TH-1 lymphocyte profile thereby suppressing cell-mediated immunity. It has been suggested that this may be an important mechanism in exercise-induced depression of immune cell function ${ }^{94}$ and in increasing susceptibility to viral infections ${ }^{92}$.

The observed tissue trauma and cytokine pattern following prolonged exercise lends some credence to this hypothesis although whether this is a causal factor in the incidence of post-exercise infection remains unknown. The theory concludes that the increased incidence of infection in some athletes with UPS is not due to a global immunosuppression but rather to an altered aspect of immune function resulting in a down-regulation of cell-mediated immunity. This theory may provide insight into the increased incidence of viral infections in some athletes with UPS since cell-mediated immunity predominantly protects against intracellular viral infections. However, this theory cannot account for the bacterial infections of the upper respiratory tract (e.g. streptococcal and staphylococcal infections), which are associated with depression of non-specific immunity and are commonly reported in athletes with OTS.

It is also possible that chronic elevation of stress hormones, particularly glucocorticoids such as cortisol, resulting from repeated bouts of intense exercise with insufficient recovery could cause temporary immunodepression even in the absence of tissue trauma. It is known that both acute glucocorticosteroid administration ${ }^{95}$ and exercise cause a temporary inhibition of IFN $-\gamma$ production by T-lymphocytes and a shift in the TH-1/TH-2 cytokine profile towards one that favours a TH-2 (humoral) response with a relative dampening of the TH-1 (cell-mediated) response.

Whilst the theories discussed above describe the possible causes of compromised immune function in OTS, the universal and most debilitating symptom in OTS is the persistent fatigue reported by athletes. A convincing theory explaining this chronic fatigue is the 'cytokine theory of overtraining' ${ }^{93,96}$. The theory proposes that the exercise-induced tissue trauma evokes a chronic inflammatory response resulting in elevated levels of cytokines in the blood and consequent 'cytokine sickness'. Cytokines communicate with the central nervous system and induce a set of behaviours referred to as 'sickness behaviour', characterised by mood changes, a disinclination to exercise and fatigue, until the inflammatory response is resolved. This is thought to be a protective mechanism as it dampens the individual's desire to expend energy in times of excessive physical and psychological stress. This theory has received some support from a study that reported elevated levels of cytokines (e.g., IL-6) in the circulation at rest at the same time as markers of muscle damage were evident in well trained triathletes undergoing periods of intensified training ${ }^{66}$ and a study that reported positive associations between elevated levels of plasma cytokines and mood disturbance (including increased sensations of fatigue) during intensified periods of training in elite rowers ${ }^{97}$.

\section{Can excessive exercise cause long lasting harm to immune function?}

There are several studies that indicate the impairment of immune function during periods of intensive training recovers within 1-2 weeks of tapering (reduced training load). However, a recent study in elite triathletes suggests that sustained high levels of training can cause a premature immunosenscence by speeding up the rate at which the thymus undergoes involution ${ }^{98}$. These authors compared the circulating levels of $\mathrm{T}$ cell receptor excision circles (TREC), a marker of recent thymic emigrants, as well as the levels of naïve and memory subsets in a group of elite endurance athletes and in recreationally active, agematched controls. While overall $\mathrm{T}$ cell numbers were unaffected, the athletes showed a reduction in absolute numbers of naïve $\mathrm{T}$ cells, particularly marked in the CD4+ T cell compartment. In contrast, numbers of memory cells were increased, more markedly in the CD8+ compartment. TREC levels in the athletes were also markedly reduced compared with the control subjects, again more markedly in the CD4+ 
compartment. Such changes resemble a premature ageing of the $T$ cell component of the immune system. Since the thymus and its production of T cells naturally decline with age, these results raise the concern that prolonging high intensity exercise into the 4th decade of life may have deleterious long term consequences for athletes' health. More research is needed to confirm these findings.

\section{Conclusions}

Resting immune function is not very different in athletes compared with non-athletes but periods of intensified training (overreaching) in already well trained athletes can result in a depression of immunity in the resting state. Illness-prone athletes appear to have an altered cytokine response to antigen stimulation and exercise. Having low levels of salivary IgA secretion makes athletes more susceptible to URTI. Overtraining is associated with recurrent infections and immunodepression is common, but immune functions do not seem to be reliable markers of impending overtraining. There are several possible causes of the diminution of immune function associated with periods of heavy training. One mechanism may simply be the cumulative effects of repeated bouts of intense exercise (with or without tissue damage) with the consequent elevation of stress hormones, particularly glucocorticoids such as cortisol, causing temporary inhibition of TH-1 cytokines with a relative dampening of the cell-mediated response. When exercise is repeated frequently there may not be sufficient time for the immune system to recover fully.

\section{Resumo}

Quando se compara a função imune, em repouso, de atletas e não atletas, não se verificam grandes diferenças. Porém, períodos de treinamento intensificado ("overreaching") em atletas bem treinados podem induzir supressão da imunidade no estado de repouso. Os atletas com maior propensão para contrair doenças parecem apresentar uma resposta alterada de citocinas, tanto quando estas são estimuladas por antígenos, quanto em resposta ao exercício propriamente dito. Baixos niveis de secreção de lgA salivar também contribuem para tornar os atletas mais susceptíveis à infecções do trato respiratório superior. A sindrome do "overtraining" é associada a infecções recorrentes e a imunossupressão é comum; no entanto, marcadores da função imune não parecem ser suficientemente sensiveis ao "overtraining" eminente. Existem várias possíveis causas para a diminuição da função imune associadas com períodos de treinamento severo. Um possivel mecanismo pode ser simplesmente, o efeito acumulativo de atividades e sessões repetidas de exercício intenso (com ou sem dano tecidual), com a consequente elevação dos hormônios de estresse, particularmente os glicocorticóides como o cortisol, causando assim, uma inibição temporária das citocinas de TH-1, com uma relativa atenuação da resposta imune celular. Quando o exercício é repetido frequentemente, pode não haver tempo suficiente para uma total recuperação do sistema imunológico. 0 "Tapering" tem sido descrito como uma gradual redução na carga de treinamento a qual permite a recuperação das capacidades fisiológicas, que por sua vez, foram afetadas pelo treinamento intensivo anterior, permitindo assim, que adaptações adicionais decorrentes do treinamento ocorram, acompanhadas pelo incremento do desempenho competitivo. A maioria dos estudos que investigaram a recuperação das respostas imuno-endócrinas em atletas durante uma a três semanas de "taper" tem registrado aumento do desempenho, frequentemente acompanhado pelo aumento da atividade anabólica, redução do estresse fisiológico e restabelecimento da imunidade das mucosas e da função imune.

PalaVRAS-CHAVE: Exercício; Treinamento; "Tapering"; Imunidade; Leucócitos; Imunoglobulinas; Atletas. 


\section{References}

1. Nieman DC. Exercise, infection and immunity. Int J Sports Med. 1994; 15:S131-41.

2. Pyne DB. Regulation of neutrophil function during exercise. Sports Med. 1994; 17:245-58.

3. Pedersen BK, Bruunsgaard H. How physical exercise influences the establishment of infections. Sports Med. 1995;19:393-400.

4. Gleeson M, Bishop NC. Immunology. In: Maughan RJ, editor. Basic and applied sciences for sports medicine. Oxford: Butterworth-Heinemann; 1999. p. 199-236.

5. Gleeson M, McDonald WA, Cripps AW, Pyne DB, Clancy RL, Fricker PA The effect on immunity of long-term intensive training in elite swimmers. Clin Exp Neuroimmunol. 1995;102:210-6.

6. Mackinnon LT. Exercise, immunoglobulin and antibody. Exerc Immunol Rev. 1996;2:1-35.

7. Shephard RJ, Shek PN. Effects of exercise and training on natural killer cell counts and cytolytic activity: a meta-analysis. Sports Med. 1999;28:177-95.

8. Pyne DB, Gleeson M. Effects of intensive exercise training on immunity in athletes. Int J Sports Med. 1998;19(Suppl 3):S183-91.

9. Fricker PA, Gleeson M, Flanagan A, Pyne DB, McDonald WA, Clancy RL. A clinical snapshot: Do elite swimmers experience more upper respiratory illness than nonathletes? Clin Exerc Physiol. 2000;2:155-8.

10. Cox AJ, Gleeson M, Pyne DB, Callister R, Hopkins WG, Fricker PA. Clinical and laboratory evaluation of upper respiratory symptoms in elite athletes. Clin J Sport Med. 2008;18:438-45.

11. Matthews CE, Ockene IS, Freedson PS, Rosal MC, Merriam PA, Hebert JR. Moderate to vigorous physical activity and the risk of upper-respiratory tract infection. Med Sci Sports Exerc. 2002;34:1242-8.

12. Peters EM, Bateman ED. Ultramarathon running and upper respiratory tract infections. An epidemiological survey. S Afr Med J. 1983;64:582-4.

13. Gleeson M, Pyne DB, Austin JP, et al. Epstein-Barr virus reactivation and upper-respiratory illness in elite swimmers. Med Sci Sports Exerc. 2002;34:411-7.

14. Nieman DC, Henson DA, Dumke CL, Lind RH, Shooter LR, Gross SJ. Relationship between salivary IgA secretion and upper respiratory tract infection following a 160-km race. J Sports Med Phys Fitness. 2006;46:158-62.

15. Spence L, Brown WJ, Pyne DB, et al. Incidence, etiology, and symptomatology of upper respiratory illness in elite athletes. Med Sci Sports Exerc. 2007;39:577-86.

16. Walsh NP, Gleeson M, Shephard RJ, et al. Position Statement Part One: immune function and exercise. Exerc Immunol Rev. 2011;17:6-63.

17. Fricker PA, McDonald WA, Gleeson M, Clancy RL. Exercise-associated hypogammaglobulinemia. Clin J Sport Med. 1999;9:46-8.

18. Gleeson M. Mucosal immune responses and risk of respiratory illness in elite athletes. Exerc Immunol Rev. 2000;6:5-42.

19. Gleeson M, Ginn E, Francis JL. Salivary immunoglobulin monitoring in an elite kayaker. Clin J Sport Med. 2000;10:206-8.

20. Fricker PA, Pyne DB. Why do athletes seem prone to infection? Med Today. 2005;6:66.

21. Reid VL, Gleeson M, Williams N, Clancy RL. Clinical investigation of athletes with persistent fatigue and/or recurrent infections. Br J Sports Med. 2004;38:42-5.

22. Gleeson M, Bishop NC. The T cell and NK cell immune response to exercise. Ann Transplant. 2005;10:43-8.

23. Michishita R, Shono N, Inoue T, Tsuruta T, Node K. Effect of exercise therapy on monocyte and neutrophil counts in overweight women. Am J Med Sci. 2010;339:152-6.

24. Hack V, Strobel G, Weiss M, Weicker H. PMN cell counts and phagocytic activity of highly trained athletes depend on training period. J Appl Physiol. 1994;77:1731-5.

25. Pyne DB, Baker MS, Fricker PA, McDonald WA, Telford RD, Weidemann MJ. Effects of an intensive 12-wk training program by elite swimmers on neutrophil oxidative activity. Med Sci Sports Exerc. 1995;27:536-42.

26. Suzuki K, Totsuka M, Nakaji S, et al. Endurance exercise causes interaction among stress hormones, cytokines, neutrophil dynamics, and muscle damage. J Appl Physiol. 1999;87:1360-7.

27. Gleeson M, Bishop NC, Stensel DJ, Lindley MR, Mastana SS, Nimmo MA. The anti-inflammatory effects of exercise: mechanisms and implications for the prevention and treatment of disease. Nat Rev Immunol. 2011;11:607-15.

28. Liao HF, Chiang LM, Yen CC, et al. Effect of a periodized exercise training and active recovery program on antitumor activity and development of dendritic cells. J Sports Med Phys Fitness. 2006;46:307-14.

29. Chiang LM, Chen YJ, Chiang J, Lai LY, Chen YY, Liao HF. Modulation of dendritic cells by endurance training. Int J Sports Med. 2007;28:798-803. 
30. Nieman DC, Nehlsen-Cannarella SL, Markoff PA, et al. The effects of moderate exercise training on natural killer cells and acute upper respiratory tract infections. Int J Sports Med. 1990;11:467-73.

31. Peters C, Lotzerich H, Niemeier B, Schule K, Uhlenbruck G. Influence of a moderate exercise training on natural killer cytotoxicity and personality traits in cancer patients. Anticancer Res. 1994;14:1033-6.

32. Nieman DC, Buckley KS, Henson DA, et al. Immune function in marathon runners versus sedentary controls. Med Sci Sports Exerc. 1995;27:986-92.

33. Woods JA, Ceddia MA, Wolters BW, Evans JK, Lu Q, McAuley E. Effects of 6 months of moderate aerobic exercise training on immune function in the elderly. Mech Ageing Dev. 1999;109:1-19.

34. McFarlin BK, Flynn MG, Phillips MD, Stewart LK, Timmerman KL. Chronic resistance exercise training improves natural killer cell activity in older women. J Gerontol A Biol Sci Med Sci. 2005;60:1315-8.

35 Fairey AS, Courneya KS, Field CJ, Bell GJ, Jones LW, Mackey JR. Randomized controlled trial of exercise and blood immune function in postmenopausal breast cancer survivors. J Appl Physiol. 2005;98:1534-40.

36. Campbell PT, Wener MH, Sorensen B, et al. Effect of exercise on in vitro immune function: a 12-month randomized, controlled trial among postmenopausal women. J Appl Physiol. 2008;104:1648-55.

37. Suzui M, Kawai T, Kimura H, et al. Natural killer cell lytic activity and CD56(dim) and CD56(bright) cell distributions during and after intensive training. J Appl Physiol. 2004;96:2167-73.

38. Morgado JM, Rama L, Matos A, et al. Cytokine production by monocytes, neutrophils and dendritic cells is hampered by long term intensive training in elite swimmers. Eur J Appl Physiol. 2012;112:471-82.

39. Nieman DC, Nehlsen-Cannarella SL. Exercise and infection. In: Watson RR, Eisinger M, editors. Exercise and disease. Boca Raton: CRC; 1992. p. 121-48.

40. Gleeson M, Ginn E, Francis JL. Salivary immunoglobulin monitoring in an elite kayaker. Clin J Sport Med 10: 206-208, 2000.

41. Pyne DB, McDonald WA, Gleeson M, Flanagan A, Clancy RL, Fricker PA. Mucosal immunity, respiratory illness, and competitive performance in elite swimmers. Med Sci Sports Exerc. 2001;33:348-53.

42. Nieman DC, Dumke CI, Henson DA, et al. Immune and oxidative changes during and following the Western States Endurance Run. Int J Sports Med. 2003;24:541-7.

43. Fahlman MM, Engels H-J. Mucosal IgA and URTI in American college football players: a year longitudinal study. Med Sci Sports Exerc.2005;37:374-80.

44. Libicz S, Mercier B, Bigou N, Le Gallais D, Castex F. Salivary IgA response of triathletes participating in the French Iron Tour. Int J Sports Med. 2006;27:389-94.

45. Nieman DC, Dumke CL, Henson DA, McAnulty SR, Gross SJ, Lind RH. Muscle damage is linked to cytokine changes following a 160-km race. Brain Behav Immun. 2005;19:398-403.

46. Nieman DC, Henson DA, Austin MD, Brown VA. Immune response to a 30-minute walk. Med Sci Sports Exerc. 2005;37:57-62.

47. Neville V, Gleeson M, Folland JP. Salivary IgA as a risk factor for upper respiratory infections in elite professional athletes. Med Sci Sports Exerc. 2008;40:1228-36.

48. Whitham M, Laing SJ, Dorrington M, et al. The influence of an arduous military training program on immune function and upper respiratory tract infection incidence. Mil Med. 2006;171:703-9.

49. Mortatti AL, Moreira A, Aoki MS, et al. Effect of comptetion on salivary cortisol, immunoglobulin A, and upper respiratory tract infections in elite young soccer players. J Strength Cond Res. 2012;26:1396-401.

50. Akimoto T, Kumai Y, Akama T, et al. Effects of 12 months of exercise training on salivary secretory IgA levels in elderly subjects. Br J Sports Med. 2003;37:76-9.

51. Klentrou P, Cieslak T, MacNeil M, Vintinner A, Plyley M. Effect of moderate exercise on salivary immunoglobulin A and infection risk in humans. Eur J Appl Physiol. 2002;87:153-8.

52. Hanson LA, Bjorkander J, Oxelius VA. Selective IgA Deficiency. In: Chandra RK, editor. Primary and secondary immunodeficiency disorders. Edinburgh: Churchill Livingstone; 1983. p. 62-4.

53. Fox PC, van der Ven PF, Sonies BC, Weiffenbach JM, Baum BJ. Xerostomia: evaluation of a symptom with increasing significance. J Am Dent Assoc. 1985;110:519-25.

54. Rossen RD, Butler WT, Waldman RH, et al. The proteins in nasal secretion. II: a longitudinal study of $\operatorname{IgA}$ and neutralizing antibody levels in nasal washings from men infected with influenza virus. JAMA. 1970;211:1157-61.

55. Gleeson M, Bishop NC, Oliveira M, McCauley T, Tauler P, Muhamad AS. Respiratory infection risk in athletes: association with antigen-stimulated IL-10 production and salivary IgA secretion. Scand J Med Sci Sports. 2012;22:410-7.

56. Tomasi TB, Trudeau FB, Czerwinski D. Immune parameters in athletes before and after strenuous exercise. J Clin Immunol. 1982;2:173-8. 
57. Gleeson M, Pyne DB. Special feature for the Olympics: effects of exercise on the immune system: exercise effects on mucosal immunity. Immunol Cell Biol. 2000;78:536-44.

58. Francis JL, Gleeson M, Pyne DB, Callister R, Clancy RL. Variation of salivary immunoglobulins in exercising and sedentary populations. Med Sci Sports Exerc. 2005;37:571-8.

59. Bishop NC, Gleeson M. Acute and chronic effects of exercise on markers of mucosal immunity. Front Biosci. 2009;14:4444-56.

60. Nieman DC. Is infection risk linked to exercise workload? Med Sci Sports Exerc. 2000;32:S406-11.

61. Verde T, Thomas S, Shephard RJ. Potential markers of heavy training in highly trained endurance runners. Br J Sports Med. 1992;26:167-75.

62. Baj Z, Kantorski J, Majewska E, et al. Immunological status of competitive cyclists before and after the training season. Int J Sports Med. 1994;15:319-24.

63. Lancaster GI, Halson SL, Khan Q, et al. Effects of acute exhaustive exercise and chronic exercise training on type 1 and type 2 T lymphocytes. Exerc Immunol Rev. 2004;10:91-106.

64. Robson PJ, Blannin AK, Walsh NP, Bishop NC, Gleeson M. The effect of an acute period of intense interval training on human neutrophil function and plasma glutamine in endurance-trained male runners. J Physiol 1999;515:84-5.

65. Lancaster GI, Halson SL, Khan Q, et al. Effect of acute exhaustive exercise and a 6-day period of intensified training on immune function in cyclists. J Physiol. 2003;548:96.

66. Robson-Ansley PJ, Blannin A, Gleeson M. Elevated plasma interleukin-6 levels in trained male triathletes following and acute period of intense interval training. Eur J Appl Physiol. 2007;99353-60.

67. Bury T, Marechal R, Mahieu P, Pirnay F. Immunological status of competitive football players during the training season. Int J Sports Med. 1998;19:364-8.

68. Rebelo AN, Candeias JR, Fraga MM, et al. The impact of soccer training on the immune system. J Sports Med Phys Fitness. 1998;38:258-61.

69. Carins J, Booth C. Salivary immunoglobulin-A as a marker of stress during strenuous physical training. Aviat Space Environ Med. 2002;73:1203-7.

70. Gomez-Merino D, Drogou C, Chennaoui M, Tiollier E, Mathieu J, Guezennec CY. Effects of combined stress during intense training on cellular immunity, hormones and respiratory infections. Neuroimmunomodulation. 2005;12:164-72.

71. Tiollier E, Gomez-Merino D, Burnat P, et al. Intense training: mucosal immunity and incidence of respiratory infections. Eur J Appl Physiol. 2005;93:421-8.

72. Mujika I, Padilla S. Scientific bases for precompetition tapering strategies. Med Sci Sports Exerc. 2003;35:1182-7.

73. Mujika I, Padilla S, Pyne D, Busso T. Physiological changes associated with pre-event taper in athletes. Sports Med. 2004;34:891-927.

74. Mujika I, Chatard JC, Geyssant A. Effects of training and taper on blood leucocyte populations in competitive swimmers: relationships with cortisol and performance. Int J Sports Med. 1996;17:213-7.

75. Mujika I, Goya A, Ruiz E, Grijalba A, Santisteban J, Padilla S. Physiological and performance responses to a 6-day taper in middle-distance runners: influence of training frequency. Int J Sports Med. 2002;23:367-73.

76. Coutts AJ, Wallace LK, Slattery KM. Monitoring changes in performance, physiology, biochemistry, ad psychology during overreaching and recovery in triathletes. Int J Sports Med. 2007;28:125-34.

77. Coutts A, Reaburn P, Piva TJ, Murphy A. Changes in selected biochemical, muscular strength, power, and endurance measures during deliberate overreaching and tapering in rugby league players. Int J Sports Med. 2007;28:116-24.

78. Coutts A, Reaburn P, Piva TJ, Rowsell GJ. Monitoring for overreaching in rugby league players. Eur J Appl Physiol. 2007;99:313-24.

79. Papacosta E, Nassis G, Gleeson M. Salivary hormones, IgA and performance during intense training and tapering in judo athletes. J Strength Cond Res. 2012 Dec 17, Epub 2012 Dec 17. PubMed PMID: 23249825.

80. Halson SL, Lancaster GI, Jeukendrup AE, Gleeson, M. Immunological responses to overreaching in cyclists. Med Sci Sports Exerc. 2003;35:854-61.

81. Farhangimaleki N, Zehsaz F, Tiidus PM. The effect of tapering period on plasma pro-inflammatory cytokine levels and performance in elite male cyclists. J Sports Sci Med. 2009;8:600-6.

82. Clancy RL, Gleeson M, Cox A, et al. Reversal in fatigued athletes of a defect in interferon gamma secretion after administration of Lactobacillus acidophilus. Br J Sports Med. 2006;40:351-4.

83. West NP, Pyne DB, Kyd JM, Renshaw GM, Fricker PA, Cripps AW. The effect of exercise on innate mucosal immunity. Br J Sports Med. 2010;4:227-31. 
84. Cox AJ, Pyne DB, Saunders PU, Callister R, Gleeson M. Cytokine responses to treadmill running in healthy and illness-prone athletes. Med Sci Sports Exerc. 2007;9:1918-26.

85. Cox AJ, Gleeson M, Pyne DB, Callister R, Fricker PA, Scott RJ. Cytokine gene polymorphisms and risk for upper respiratory symptoms in highly-trained athletes. Exerc Immunol Rev. 2010;16:8-21.

86. Meeusen R, Duclos M, Foster C, et al. Prevention, diagnosis and treatment of the Overtraining Syndrome. Joint consensus statement of the European College of Sport Science (ECSS) and the American College of Sports Medicine (ACSM). Eur J Sport Sci. 2013;13:1-24.

87. Kingsbury KJ, Kay L, Hjelm M. Contrasting plasma amino acid patterns in elite athletes: association with fatigue and infection. Br J Sports Med. 1998;32:25-33.

88. Newholme EA. Biochemical mechanisms to explain immunosuppression in well-trained and overtrained athletes. Int J Sports Med. 1994;15:S142-7.

89. Keast D, Arstein D, Harper W, Fry RW, Morton AR. Depression of plasma glutamine concentration after exercise stress and its possible influence on the immune system. Med J Aust. 1995;162:15-8.

90. Rowbottom DG, Keast D, Goodman C, Morton, AR. The haematological, biochemical and immunological profile of athletes suffering from the Overtraining Syndrome. Eur J Appl Physiol Ocupp Physiol. 1995;70:502-9.

91. Pedersen BK, Ullum H. NK cell response to physical activity; possible mechanisms of action. Med Sci Sports Exerc. 1994;26:104-46.

92. Smith LL. Overtraining, excessive exercise, and altered immunity: is this a T Helper-1 versus T Helper-2 lymphocyte response? Sports Med. 2003;33:347-64.

93. Smith LL. Tissue trauma: the underlying cause of overtraining syndrome? J Strength Cond Res. 2004;18:185-93.

94. Northoff H, Berg A, Weinstock C. Similarities and differences of the immune response to exercise and trauma: the IFN-gamma concept. Can J Physiol Pharmacol. 1998;76:497-504.

95. Moynihan JA, Callahan TA, Kelley SP, Campbell LM. Adrenal hormone modulation of type 1 and type 2 cytokine production by spleen cells: dexamethasone and dehydroepiandrosterone suppress interleukin-2, interleukin-4, and interferon-gamma production in vitro. Cell Immunol. 1998;184:58-64.

96. Smith LL. Cytokine hypothesis of overtraining: a physiological adaptation to excessive stress? Med Sci Sports Exerc. 2000;32:317-31.

97. Main LC, Dawson B, Heel K, Grove JR, Landers GJ, Goodman C. Relationship between inflammatory cytokines and self-report measures of training overload. Res Sports Med. 2010;18:127-39.

98. Prieto A, Knight A, Compton C, Gleeson M, Travers PJ. Premature immune sensescence in elite athletes. J Immunol. Forthcoming 2013.

\begin{tabular}{r|r} 
ENDEREço & \\
Michael Gleeson & \\
School of Sport, Exercise and Health Sciences & \\
Loughborough University & \\
Loughborough & Recebido para publicação: 16/01/2013 \\
Leicestershire & Aceito: 20/01/2013 \\
LE11 3TU & \\
UNITED KINGDON & \\
e-mail: M.Gleeson@Iboro.ac.uk &
\end{tabular}

176 • Rev Bras Educ Fís Esporte, (São Paulo) 2013 Jan-Mar;27(1):159-76 